\title{
TOWARDS A CONCEPTUAL FRAMEWORK FOR PROPERTY LEVEL FLOOD RESILIENCE
}

\author{
TAIWO J. ADEDEJI ${ }^{1}$, DAVID G. PROVERBS ${ }^{1}$, HONG XIAO$^{1} \&$ VICTOR O. OLADOKUN ${ }^{2}$ \\ ${ }^{1}$ Faculty of Computing, Engineering and the Built Environment, Birmingham City University, UK. \\ ${ }^{2}$ Industrial and Production Engineering, University of Ibadan, Nigeria.
}

\begin{abstract}
Resilience is a multifaceted field of study that has been addressed by different disciplines and has been the subject of extensive research. Despite this vast body of research, there is no agreement on a single definition among researchers. Resilience in the context of flooding has become a major focus of flood risk management policy and reflected in current strategy to mitigate the effects of flooding. Furthermore, in recent times, increased attention has been given to property level resilience as part of an integrated approach to flood risk management. Despite this focus on resilience to flooding, there lacks a single definition and consequently, any effective means to quantify and measure resilience at the level of the individual property. This study aims to review and synthesize the concepts of resilience applied in different fields, in order to propose a resilience definition in the context of property level flood resilience. A framework for conceptualising flood resilience in residential property is developed which indicates the associated components and variables. The framework has the potential to be used by a range of key stakeholders in helping to understand current levels of property level resilience and in deciding what interventions might be best considered to improve resilience.

Keywords: outcome-based approach, process-based approach, property flood resilience, resilience theory.
\end{abstract}

\section{INTRODUCTION}

The term resilience is derived from the Latin word resilire which means to bounce back or to recoil, a word that has enjoyed prominence in terms of research for the past four decades [1]. Resilience theory is a many-sided field of study that has been addressed by psychologists, sociologists, ecologists and many others over the past few decades addressing the strengths that people and systems demonstrate to enable them to rise above adversity [2]. About fifty years of research in resiliency has seen a lot brought forward in both perspectives and opinions [3, 4]. Despite this vast body of knowledge on resilience, there is no agreement on a single definition among researchers and, inevitably, different definitions have been offered [5]. This lack of consensus has resulted into conceptual divergence or pluralism when the notion is applied to any phenomenon [6]. Thus the concept of resilience has been seen from different points of view and in different contexts [7]. Owing to these developments, this paper aims to review and synthesize these concepts of resilience theory applied in different fields and, based on this, propose a resilience definition in the context of property flooding.

\section{RESILIENCE IN VARIOUS FIELDS}

While, the field of resilience is broad and diverse [2], the concept is still evolving and has been developing in various fields [7]. In some aspects the term is well developed and explored, while in others it is still nascent [2]. The way the term is conceptualized by each discipline is evident in the fundamental beliefs and principles that govern them. The different views to resilience as offered by several disciplines are presented in subsequent sections with reference to definitions and the concepts. 


\subsection{Psychological Resilience}

In the early 1970s, the term 'resilience' began to be used as a substitute for stress resistance in psychological studies of children. However, it soon became a regularly used term in psychology, with the word stress often referred to as adversity or trauma. These words continue to appear in many definitions of resilience, at times in different forms. According to the American Psychological Association [8], resilience is seen as the process of adapting well in the face of adversity, trauma, tragedy, threats or even significant sources of stress. Also, as cited by Gauvin-Lepage [9] resilience is seen from a similar standpoint as the capacity to withstand traumatic situations and the ability to use such situations to start something new. This definition is a combination of coping and adaptive abilities of the subject in question. The focus of psychological resilience is mostly human. Masten [10] attested to this when he directly referred resilience to people from high risk groups with better outcomes than expected, good adaptation in spite of adversity and quick recovery from trauma. This was echoed by Hardy et al. [11] as they also associated the term resilience to people, acknowledging resilient people as those individuals who can show the ability to remain in good shape, recover, or even thrive in face of adversity.

Resilience has become an umbrella term to cover many different aspects of overcoming the adversities and adapting to one's environment [12]. However, there is little consensus as on the definition of resilience. In psychology, resilience has been conceptualized in several ways. It is conceived by some as a set of traits, others as a process or even an outcome [13] but arguably it can function in any of these capacities. Resilience has been conceptualized from four interrelated but distinct views which are (a) as good outcomes in the face of adversity; (b) as persistent competence under stress; (c) as recovery from trauma and (d) as the interaction between protective and risk factors $[14,15]$. This variability in the application of the construct of resilience has led to some confusion and controversy in the definition and utility of resilience. It has also raised concern on whether it is a valuable construct that can be empirically examined, studied and utilized in interventions [12]. It is arguable whether or not resilience is an innate quality which produces an outcome or dynamic process evident in the literature [16].

\subsection{Resilience in Ecological Perspective}

Ecological science has been largely influenced by the biological sciences while the environmental science has been shaped largely by the physical sciences and engineering [17]. With the beginning of interdisciplinary efforts between the two fields, some of their fundamental differences began to generate conflict which was caused by a misunderstanding of basic concepts rather than by the difference in social purposes or methods [17]. These biases are obvious in their views of the term resilience.

In the ecological literature, resilience has been defined basically in two different ways, namely, engineering and ecosystem resilience, each reflecting different aspects of stability [18] and clearly highlighting the basic concepts of the discipline from which it emanates. The subsequent sections take a close review of these two aspects of the ecological resilience first independently and then drawing attention to the contrasting view of both.

\subsubsection{Engineering Resilience}

Holling [18] draws a distinction between resilience and stability, and defines resilience as the ability of a system to return to its stable state after a momentary disturbance. Hollnagel [19] 
gives a similar definition of resilience as bringing ecological systems to exist close to a stable steady-state. The approach however seems to revolve around a system's ability to return to the steady-state after being disturbed without assuming an entirely new position. Hence, this places resilience and stability as two important properties of ecological systems, as regards defining engineering resilience, which are measured by the system's speed of return to stability and the amount of disturbance required to take it off stability [20,21]. However, in a bid to measure these properties, some core engineering attributes for fail-safe design, such as predictability, constancy and efficiency, have become the focal point. According to de Bruijn et al. [22], sustaining a function and the conservation of an existing situation are fundamentals to engineering resilience.

This engineering approach to measuring resilience has been referred to as the traditional, old dominant perspective which indirectly assumed there will be a stable and an infinitely resilient environment where the flow of resource could be controlled and that naturally things will go into equilibrium as soon as the human stressors are removed [21]. However, in reality, change has been part of life, including climate change, and to keep a system stable and infinitely resilient will require apt consideration of uncertainty. Yet, the view has provided one of the foundations for economic theory [17]. It has also found its way into the safety management purview. In the early 2000s, safety specialists started using resilience engineering to describe an alternative approach of dealing with safety issues, accidents as well as risks and also focusing on helping people cope with complexity under pressure to achieve success $[19,23]$. In the safety management domain it has been defined as the inherent ability of a system to adjust its functioning before, during, or after exposure to disturbances, so that it can sustain required operations under both expected and unexpected conditions [24]. The acceptability of resilience into other fields of study highlights its relevance, most especially in the domain of safety management where it has become a paradigm [25].

\subsubsection{Ecological Resilience}

Much work on resilience has concentrated on the capacity to absorb shocks and still maintain function, which defines the qualities of the engineering resilience [21]. However, there is also another aspect of resilience that concerns the capacity for regeneration, re-organization, adaptation and development, which has been less in focus but is essential for the sustainability discourse [26]. The later kind of resilience has been termed the ecosystem resilience and mostly referred to as the ecological resilience. According to Holling [18] this kind of resilience measures the ability of an ecosystem to absorb changes and still exist. Unlike the engineering resilience, ecological resilience underscores conditions that deviate from any stable steady-state, where instabilities can flip a system from one regime of behaviour into another, resulting to a new equilibrium position [18]. According to Hollnagel [19], this kind of resilience is measured based on the magnitude of the disturbance that can be absorbed before the system assumes a new position by changing the variables and processes that control behaviour.

Hence, in this approach, the useful measure of resilience is the size of stability domains, or more meaningfully, the limit of disturbance a system can accommodate before its controls shift to another set of variables and relationships that dominate another stability region [21]. Here, the relevant focus is not on constancy but on variability [21]. The attributes that defines this kind of approach are unpredictability, persistence and change [18], attributes embraced by biologists with an evolutionary perspective and by those who search for safe-fail designs [17].

It is argued that managing resilience enhances the likelihood of sustaining desirable pathways for development in changing environments where the future is unpredictable and 
surprise is likely [27, 28]. However, resilience in ecological systems is not easily observed, and there seems at present to be no agreed relationship, for example, between the diversity of ecosystems and their resilience [29].

\section{DIMENSIONS OF RESILIENCE, AS AN OUTCOME OR A PROCESS}

The previous section presents resilience as it is seen in different fields, Psychology, Engineering and Ecology, while subsequent sections present the approaches that have been adopted in conceptualising resilience. The concept has been applied majorly in two ways across these disciplines. Kaplan [30] simply put it as a concept generally defined in two broad ways: as a desired outcome or as a process leading to a desired outcome. Though, Manyena [31] admitted that classifying the numerous definitions of resilience as outcome- or process-oriented is not an easy task, however, understanding the distinction between these dimensions is key to conceptualising resilience in any domain particularly flooding.

Outcome focused resilience typically emphasizes the maintenance of functionality; that is, patterns of competent behaviour or effective functioning [32]. It seeks to observe explicit end points of the structure put in place to ensure that a system continues to function. In this dimension, resilience depends on properties such as a system's capacity to withstand a disturbance without functional failure, the degree to which system components are substitutable, and the speed of recovery after being displaced by disturbance $[33,34]$. This outcome-based perspective highlights the importance of understanding competing resilience outcome priorities - such as determining when the system has begun to stabilize after an event and restore damaged resources [35]. According to Manyena [31], this makes the approach a command and control panache that risk preserving the status quo. The concept has been adopted in the domain of disaster reduction emphasizing recovery from shocks and retaining the status quo [36].

Meanwhile, in the process dimension, resilience is measured in actions, rather than system properties [24]. This measurement involves what the system does such as the way it senses, anticipates, adapts, learns, or functions at all times and specifically in response to disturbance. Process-based resilience is an emergent behaviour of a complex adaptive system [37] which reflects the degree to which these systems are capable of self-organization and building the capacity for learning and adaptation [21]. Essentially, the focus of the process-based resilience is to understand the mechanisms that makes a system adjust and successfully adapt to the impact of a risk setting [32]. This concept of resilience has been adopted in the domain of climate change adaptation as a way to deal with both gradual, disturbing changes and shocks [38].

Both dimensions have been applied to resilience in the field of psychology. However, the outcome based approach is predominantly applied in Engineering where it adopts the recovery capacity while in ecology, the process-based approach is adopted to conceptualise resilience, mainly as an adaptive capacity. A summary of these dimensions of resilience and their interpretation across different disciplines is shown in Table 1.

\section{DEFINITION OF RESILIENCE IN PROPERTY FLOODING}

While flooding is a natural occurrence that brings both adverse and beneficial environmental changes [39], when it happens to any property its impact is mostly adverse. Flooding of property will almost always involve water entering the building from outside [40] with several means by which external flood water can gain entrance. This ingress can cause serious damage to the property and its contents as well as the structure. The chances of water gaining entrance will depend on factors like the depth of flood water and the time it takes to drain 
Table 1: Dimensions of Resilience in different disciplines.

\section{DIMENSION OF RESILIENCE}

\begin{tabular}{lll}
\hline DISCIPLINES & Outcome-based & Process-based \\
\hline Psychology & $\begin{array}{l}\text { effective functioning of young people } \\
\text { exposed to risk } \\
\text { ability to recover from disturbance }\end{array}$ & $\begin{array}{l}\text { positive adaptation in the face } \\
\text { adversity }\end{array}$ \\
Engineering & & $\begin{array}{l}\text { capacity to absorb disturbance } \\
\text { and adapt }\end{array}$ \\
\hline
\end{tabular}

away [40]. Mostly, these considerations tends to focus only on the physical structure, i.e. the building [41], however, the human component also merits consideration.

In order to quantify property level flood resilience, the human component needs to be included since the individual property is not built in isolation of humans. It is built to serve as shelter for human and as a result, if it's at the risk of flooding, the residents are equally at risk. In order to give resilience a definition in the context of property flooding, it is essential to recognise that the essence of resilience is to reduce risk exposure and the extent of potential damage to both components. The amount of flood protection measures necessary will depend on the degree of flood risk, and the vulnerability of the property and its occupants. In other words, to have a good understanding of flood risk, it is vital to identify the ways in which floods can damage buildings and, equally, the way this damage can be minimised [42]. In a bid to define resilience in property flooding, the next sections attempt to explore the resilience disciplines that address each of these components and the approach to apply. Finally, the variables that describes resilience in each component is examined.

\subsection{A Hybrid Approach}

Based on the definition given to property as the combination of the building and its residents, it becomes pertinent to state that each of these components requires a different approach of safeguarding. This is due to the differences that exist in both components.

The engineering approach to resilience is been regularly applied in the purview of architecture and building technology, and when applied to the context of property flooding, it comprises of the resistance of building to and recovery from the impact of flooding [43, 44]. The norms of engineering designs, materials, and retrofit strategies have been developed to protect the physical integrity of building and to enhance its ability to withstand flooding [45]. These designs and engineering standards define the limit of the building as regards its resilience to flood characteristics. The level of resilience is determined by the speed of recovery of building to full inhabitable state. Meanwhile, when the flood risk exposure is higher than the building is designed for, recovery becomes difficult. Apparently, the focus of the measurement is entirely on recovery [43]. This makes it difficult to apply the process-based approach where adaptability is required; and the building can learn from the flood action and adjust itself to a new regime and yet maintain desired functioning. Buildings do not have minds of theirs own except the one put in place by the engineers and developers. To this end, the outcome-based approach is appropriate as it presents the essence of these design in terms of recovery 
However, the resilience of the residents require a different approach. A person's ability to mentally and emotionally get back on track from flood impact does not, however, mean that he/she will simply return to his/her original state [46]. The plasticity of the human being mind and body - permits adaptive responses to the impact of flooding. The resilience of a building (physical structure) alone is however, not sufficient to convene resilience to the entire system of the property flooding, made of both the building and its residents. Therefore, the outcome-based approach applied for the building resilience is not appropriate for human resilience, because of the dynamic nature of the human mind. For humans, the general focus of resilience has been to understand how individuals deal with internal or external forces of change without compromising their well-being [47]. Across the literature it has been emphasized that the psychological wellbeing of an individual under stresses speaks a lot about his ability to change continually and adapt [48]. At an individual level, the psychological wellbeing of residents confers considerable protection [49]. Resilience does not only result from recovery from stress but also the ability of individuals to anticipate the changing shape of risk before the occurrence of failures and harm. Meanwhile, unlike buildings, every individual can decide on how he or she responds to the impact of flooding. The decision defines their resilience. This approach is process-based where resilience is viewed as a deliberate process leading to desired outcomes [31].

Consequently, resilience is seen as a quality, characteristic or result that is generated (as in the case of the building resilience) or developed by the processes that foster or promote it (as in the case of the human resilience). Based on the foregoing discussion, a new hybrid framework is developed to conceptualise property level flood resilience (see Fig. 1). This hybrid framework contains the two components that make up the individual property, the building and the human components. Each component is embedded within the appropriate discipline and approach. As shown in the figure, the human component is embedded in the psychological resilience and within the process-based resilience dimension. However, as depicted by the double-edge arrow in the conceptual framework, the building component interacts with the human component. This implies that whatever decision or action (process-based) taken to enhance the human resilience, will affect the rate of recovery of the building (outcomebased). For instance, an individual who purchases flood insurance has taken a step that will enhance their resilience [31] and also a decision that will impact the overall outcome of the building resilience. Similarly, a building with a poor recovery capacity will impact the level of changes required and the action taken by humans to adapt to such situation. According to Lock et al. [50] it is important to know that the stress and strain associated with dealing with cleaning up of homes and recovery may also be a problem [50]. Therefore, an individual who finds themselves in this kind of situation may develop their adaptive capacity to alleviate the mental stress resulting from the disruption and upheaval.

The outcome-based resilience, applied in the engineering field is conceived as the ability of the building to resist shocks and remain in the same state [45]. It emphasises on resisting, coping with and recovering from flood impact. According to Eriksen and Kelly [51], this approach addresses the question: What can be done to protect the building and its content from the impact of flooding? While the process-based resilience applied in the psychological resilience tends to address the question: What should be done to fortify the residents' capacity to respond and adapt to flood risk exposure? Process-based resilience is used to build adaptive capacity, where it is needed to monitor the progress in implementing adaptation measures.

However, there is yet an agreement in the literature on the role each of these two kinds of approaches should play. Recognising resilience as a process only rather than an outcome 
weakens some of the prevalent efforts to quantify resilience [52]. Although current resilience research often places emphasis on one dimension at the expense of others [53], Harley et al. [54] believe that both the process-based and outcome-based approaches will have to be combined in order to monitor the progress in adaptation. This is important when considering property level flood resilience, where both recovery of property and adaptability of residents is necessary.

\subsection{Variables Selection}

Another critical stage in the definition is the identification and selection of variables that represent each of these components. Flood resilience is an applied, complex area with multiple actors and variables [55]. According to Thurston et al. [56] the generic term, property level flood risk variables covers sources of information relating to flood history, flood risk and flood mitigation for the residential properties and its residents. The geographical and hydrological data are foundational for the establishment of a flood risk assessment system [57]. These data are mostly the flood characteristics and are presented in Fig.1 representing the conceptual framework. The flood properties domain contains the building and human components which indicates that both components are affected by the characteristics of the flood risk exposure.

The Environmental Agency has collaborated with experts in many fields to develop models that enables the evaluation of some of these properties like the flood depth, velocity and duration. Also, as regards to the relative intensity and frequency of potential flood events, some organisations and experts have made certain data available [56]. Meanwhile, a range of products is available in assessing these data at individual property level, these including the Flood Map, historical flood event outlines, National Property Dataset (NPD 2008), National Flood Risk Assessment (NaFRA) products and flood risk assessment (FRA) products [56]. These flood characteristics and associated data are key to assessing the property level resilience

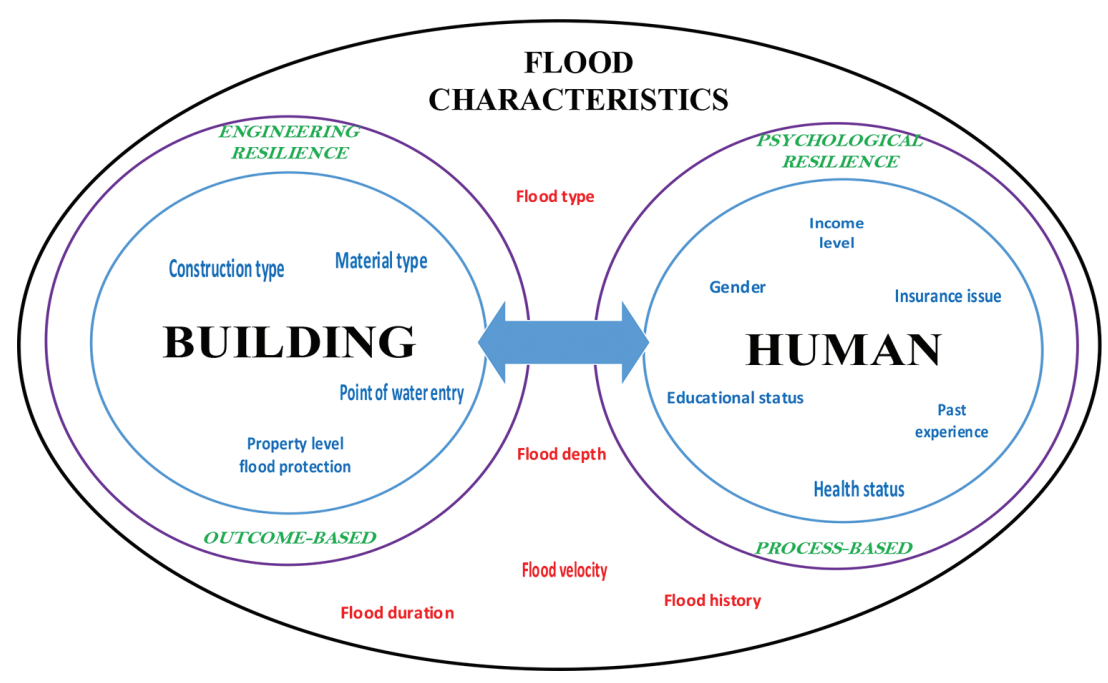

Figure 1. Conceptual Framework for Property Level Flood Resilience. 
with the property resilience viewed as the ability of both the building and residents to cope with the impact of the flood properties.

The data/information that provides insight on the resilience of the physical building to flooding include; building material and construction type, the likely points of water entry; availability of resistance and resilience measures referred to as property level flood protection $[40,41]$. These are essential because, the water retention capacity of material differs. For instance, dense materials retain little water but dry slowly, whereas porous materials can retain large amounts of water but can often be dried quickly. Also, some types of construction and the addition of extensions can result in voids being created within the fabric of a building. Owing to Lamond et al. [58] classification of property level flood protection is an essential element of modern flood risk management strategy, it is safe to conclude that these information are relevant for the assessment of resilience of the building, structurally and in terms of safeguarding its contents.

For the resilience of humans (i.e. the occupants) to a flood event, it is clear that the human coping ability differs and certain factors have been identified as responsible for influencing the way humans deal with the impact of flooding. Some of these factors are gender, age, education level, employment status, nationality, health status [59,60]. Research has been carried out to examine the health impact of flooding on individuals with some of these characteristics [61]. In fact, research done on gender has shown that the impact of floods on men and women is different and distinct [62]. Studies suggest that women or girls may be at greater risk than men or boys of mental health problems following exposure to flood disaster [63].

The human resilience can be increased by better preparation and building capacity to resist floods or to reduce the impacts. These could be achieved by understanding how these factors influence reaction to flood impact. As suggested by the Pitt Review, resilience, in terms of flooding, can be defined as the capacity of a person to anticipate, cope with, resist and recover from the impact of a flood [64].

\section{CONCLUSIONS}

Resilience is a vague concept that is understood and interpreted differently across disciplines (psychology, engineering and ecology). This review has shown how these disciplines have conceptualised resilience either as an outcome or a process. Also, a new way of defining property level flood resilience has been introduced, with the individual property viewed as a combination of the building (physical structure) and residents (human). Previous attempts to define property level resilience have been made but these earlier frameworks have tended to focus on either the building or the human element. A new conceptual framework has been developed which combines both components, and adopts a hybrid approach of conceptualising resilience. This is important as it provides an opportunity to see how changes in human resilience affects the outcome of the building resilience and vice versa.

The framework will be of importance to all stakeholders of property and can be utilised in understanding current levels of resilience and in deciding how best to improve this. The framework has the potential of providing valuable information to homeowners, in understanding how to protect their properties and themselves against the impact of flooding; property experts in offering good advice; estate agents and surveyors in property valuation; and government with policy making. The development of the framework is part of an ongoing study to measure resilience at the individual property level and further work will be done to test and validate the framework. 


\section{REFERENCES}

[1] Fleming, J. \& Ledogar, R.J., Resilience, an evolving concept: a review of literature relevant to aboriginal research. PubMed Central, 6(2), pp. 7-23, 2008.

[2] VanBreda, A.D., Resilience Theory: A Literature Review. Pretoria, South Africa: South African Military Health Service, Military Psychological Institute, 2001.

[3] Thomsen, K., Building Resilient Students, Corwin Press, Inc, . Thousand Oaks, CA, 2002.

[4] Unger, M., Handbook for Working with Children and Youth. Sage Publications, Thousand Oaks, CA, 2005.

[5] Djordjević, S., Butler, D., Gourbesville, P., Mark, O. \& Pasche E., New policies to deal with climate change and other drivers impacting on resilience to flooding in urban areas: the CORFU approach. Environmental Science \& Policy, 14(7), pp. 864-873, 2011.

https://doi.org/10.1016/j.envsci.2011.05.008.

[6] Desjardins, E., Barker, G., Lindo, Z., Dieleman, C. \& Dussault A.C., Promoting Resilience. The Quartely Review of Biology, 90(2), pp. 147-165, 2015. https://doi.org/10.1086/681439.

[7] Hosseini, S., Barker, K. \& Ramirez-Marquez, J.E., A review of definitions and measures of system resilience. Reliability Engineering \& System Safety, 145, pp. 47-61, 2016.

https://doi.org/10.1016/j.ress.2015.08.006

[8] American Psychological Association., The Road to Resilience. American Psychological Association, Washington, DC, 2014.

[9] Gauvin-Lepage, J., Lefebvre, H. \& Malo, D., Family resilience: defining the concept from a humanist perspective. Interdisciplinary Journal of Family Studies, 19(2), pp. 22-36, 2014.

[10] Masten, A., Resilience in individual development: successful adaptation despite risk and adversity. Educational Resilience in Inner-City American: Challenges and Prospects, eds. M.C. Wang \& E.W. Gordon. Lawrence Erlbaum, Hillsdale, NJ, pp. 3-26, 1994.

[11] Hardy, S.E., Concato, J. \& Gill, T.M., Resilience of community-dwelling older persons. American Geriatrics Society, 52(2), pp. 257-262, 2004. https://doi.org/10.1111/j.1532-5415.2004.52065.x.

[12] McCubbin, L., Challenges to the Definition of Resilience, San Francisco, California: American Psychological Association, 2001.

[13] Ahern, M., Kovats, RS., Wilkinson, P., Few, R. \& Matthies F.,.Global health impacts of floods: epidemiologic evidence. Epidemiol Reviews, 27(1), pp. 36-46, 2005. https://doi.org/10.1093/epirev/mxi004.

[14] Kumpfer, K., Resiliency and AOD Use Prevention in High Risk Youth. Unpublished manuscript ed. Salt Lake City, Utah, 84112: Available from School of Social Work, University of Utah, 1993.

[15] Norman, E., Introduction: the strengths perspective and resiliency enhancement: a nature partnership. Resiliency Enhancement: Putting Thestrengths Perspective Into Social Work Practice. In: E.Norman, ed. New York, NY: Columbia University Press, pp. 1-16, 2000.

[16] Santos, R.S. \& Dreyer, P., Why resilience?" A Review of Literature of Resilience and Implications for Further Educational Research. Running Head: Review of Resilience Research, 2012.

[17] Holling, C.S.,Engineering resilience versus ecological resilience. Engineering Within Ecological Constraints. ed. P. Schulze. National Academy Press, Washington DC, pp. 31-44, 1996.

[18] Holling, C., Resilience and stability of ecological systems. Annual Review of Ecology and Systematics, 4(1), pp. 1-23, 1973.

https://doi.org/10.1146/annurev.es.04.110173.000245 
[19] Hollnagel, E., Resilience engineering and the built environment: Building Research and Information, Taylor and Francis, Denmark, 2013.

[20] de Bruijn, K.M., Resilience indicators for flood risk management systems of lowland rivers. International Journal of River Basin Management, 2(3), pp. 199-210, 2004. https://doi.org/10.1080/15715124.2004.9635232

[21] Folke, C., Resilience: the emergence of a perspective for social-ecological systems analyses. Global Environmental Change, 16, pp. 253-267, 2006.

https://doi.org/10.1016/j.gloenvcha.2006.04.002

[22] de Bruijn, K,. Buurman, J., Mens, M., Dahm R. \& Klijn F., Resilience in practice: five principles to enable societies to cope with extreme weather events. Environmental Science and Policy, 70, pp. 21-30. 2017. https://doi.org/10.1016/j.envsci.2017.02.001.

[23] Woods, D.D., Designing for resilience in the face of change and surprise: creating safety under pressure. Plenary Talk, Design for Safety Workshop, NASA Ames Research Center, 10 October, 2000.

[24] Hollnagel, E., Paries, J., Woods, D.D. \& Wreathall, J.,Resilience Engineering in Practice: A Guidebook. Farnham, UK: Ashgate, 2011.

[25] Woods, D.D. \& Hollnagel, E., Resilience Engineering: Concepts and Precepts, CRC Press, Boca Raton, 2006.

[26] Gunderson, L.H. \& Holling, C.S., Panarchy: Understanding Transformations in Human and Natural Systems, Island Press, Washington DC, 2002.

[27] Walker, B., Holling, C.S., Carpenter, S.R. \& Kinzig, A.P.,Resilience, adaptability and transformability in social-ecological systems. Ecology and Society, 9(2), pp. 5-13, 2004.

https://doi.org/10.5751/es-00650-090205

[28] Adger, W.N.,Social-ecological resilience to coastal disasters. Science, 309(5737), pp. 1036-1039, 2005.

https://doi.org/10.1126/science.1112122

[29] Tilman, D., Biodiversity and ecosystem functioning. Nature's Services: Societal Dependence On Natural Ecosystems. ed. G.C. Daily. Washington, DC: Island Press, pp. 93-112, 1997.

[30] Kaplan, H.B., Toward an understanding of resilience: a critical review of definitions and models. Resilience and Development: Positive Life Adaptations, eds. M. Glantz \& J. Johnson, Plenum Press, New York, 1999.

[31] Manyena, S.B.,The concept of resilience revisited. Disasters, 30(4), pp. 433-450, 2006. https://doi.org/10.1111/j.0361-3666.2006.00331.x

[32] Olsson, C.A., Bond, L., Burns, J.M., Vella-Brodrick, D.A. \& Sawyer S.M., Adolescent resilience: a concept analysis. Journal of Adolescence, 26(1), pp. 1-11, 2003. https://doi.org/10.1016/s0140-1971(02)00118-5

[33] Bruneau, M., Chang, S.E., Eguchi, R.T., Lee, G.C., O'Rourke, T.D., Reinhorn, A.M., Shinozuka, M., Tierney, K. \& Wallace, W.A., A framework to quantitatively assess and enhance the seismic resilience of communities. Earthquake Spectra, 19(4), pp. 733$752,2003$. https://doi.org/10.1193/1.1623497

[34] Liao, K.H., A theory on urban resilience to floods-a basis for alternative planning practices. Ecology and Society, 17(4), p. 48, 2012.

https://doi.org/10.5751/es-05231-170448 
[35] McDaniels, T., Chang, S., Cole, D., Mikawoz, J. \& Longstaff, H., Fostering resilience to extreme events within infrastructure systems: characterizing decision contexts for mitigation and adaptation. Global Environmental Change, 18(2), pp. 310-318, 2008. https://doi.org/10.1016/j.gloenvcha.2008.03.001

[36] Mayunga, J.S.,Understanding and applying the concept of community disaster resilience: a capital-based approach. Summer Academy for Social Vulnerability and Resilience Building, pp. 1-16, 2007.

[37] Park, J., Seager, T.P., Rao P.S.C., Convertino M. \& Linkov I., Integrating risk and resilience approaches to catastrophe management in engineering systems. Risk Analysis, 33(3), pp. 356-367, 2013.

https://doi.org/10.1111/j.1539-6924.2012.01885.x

[38] Linkov, I., Bridges, T., Creutzig, F., Decker, J., Fox-Lent, C., Kröger, W., Lambert, J.H., Levermann, A., Montreuil, B., Nathwani, J., Nyer, R., Renn, O., Scharte, B., Scheffler, A., Schreurs M. \& Thiel-Clemen, T., Changing the resilience paradigm. Nature Climate Change, 4(6), pp. 407-409, 2014.

https://doi.org/10.1038/nclimate2227

[39] Gautam, K.P. \& van der Hoek, E.E., Literature Study on Environmental Impact of Floods, Delft Cluster Publication, Netherland, 2003.

[40] Dhonau, M. et al., Homeowners Guide to Flood resilience a Living Document, England: MDA, 2016.

[41] ODPM.,Preparing for Flood: Interim guidance for improving the flood resistance of domestic and small business properties, Office of the Deputy Prime Minister, London, UK, 2003.

[42] Lamond, J.E.,The Impact of Flooding on the Value of Residential Property in the UK, University of Wolverhampton, Wolverhampton, UK, 2008.

[43] Hollnagel, E., Memeth, C.P. \& Dekker, S.,Resilience Engineering Perspectives. Remaining Sensitive to the Possibility of Failure, 1st ed., Ashgate, Burlington: Vermont, USA, 2008.

[44] Garvin, S.,Flood Resilient Building - Part 2: Building in Flood-Risk Areas and Designing Flood-Resilient Buildings, BRE Press, Watford, 2012.

[45] Kallaos, J., Wyckmans, A. \& Mainguy, G., Synthesis Review on Resilient Architecture and Infrastructure Indicators, RAMSES Project, 2014.

[46] Almedom, A.M.,Resilience: Outcome, Process, Emergence, Narrative (OPEN) theory. On the Horizon, 21(1), pp. 15-23, 2013.

https://doi.org/10.1108/10748121311297030

[47] Chuang, W.C., Garmestani, A., Eason, T.N., Spanbauer, T.L., Fried-Petersen, H.B., Roberts, C.P., Sundstrom, S.M., Burnett, J.L., Angeler, D.G., Chaffin, B.C., Gunderson, L., Twidwell, D. \& Allen, C.R., Enhancing quantitative approaches for assessing community resilience. Environmental Management, 213, pp. 353-362, 2018. https://doi.org/10.1016/j.jenvman.2018.01.083

[48] Berkes, F. \& Ross, H., Community resilience: toward an integrated approach. Society and Natural Resources, 26, pp. 5-20, 2012.

https://doi.org/10.1080/08941920.2012.736605

[49] Friedli, L., Mental Health, Resilience and Inequalities, World Health Organisation, Denmark, 2009.

[50] Lock, S., Rubin, G.J., Murray, V., Rogers, M.B., Amlot, R. \& Williams, R., Secondary stressors and extreme events and disasters. PLOS Disasters, 2012.

https://doi.org/10.1371/currents.dis.a9b76fed1b2dd5c5bfcfc13c87a2f24f 
[51] Eriksen, S.H. \& Kelly, P.M., Developing credible vulnerability indicators for climate adaptation policy assessment. Mitigation and Adaptation Strategies for Global Change, 12, pp. 495-524, 2007. https://doi.org/10.1007/s11027-006-3460-6

[52] Birkmann, J. Chang-Seng, D., Abeling, T., Huq, N., Wolfertz, J., Karanci, N., İkizer, G., Kuhlicke, C., Pelling, M., Forrester, J., Fordham, M., Deeming, H., Kruse, S. \& Jülich, S., Systematization of Different Concepts, Quality Criteria, and Indicators, RAMSES Project, 2012.

[53] Snell, M.L., Eisenberg, D.A., Seager, T.P., Clark, S.S., Oh, Y.H., Thomas, J.E. \& McBurnett, L.R., A Multidimensional Review of Resilience: Resources, Processes, and Outcomes, International Risk Governance Center (IRGC), Lausanne, 2016.

[54] Harley, M., Horrocks, L., Hodgson, N. \& van Minnen, J., Climate change vulnerability and adaptation indicators. The European Topic Centre on Air and Climate Change (ETC/AC), EEA, Bilthoven, NL, 2008.

[55] Twigger-Ross, C., Kashefi, E., Weldon, S., Brooks, K., Deeming, H., Forrest, S., Fielding, J., Gomersall, A., Harries, T., McCarthy, S., Orr, P., Parker, D. \& Tapsell, S. Flood Resilience Community Pathfinder Evaluation: Rapid Evidence Assessment, Defra, London, 2014.

[56] Thurston, N., Finlinson, B., Breakspear, R., Kidd, B., Glerum, J., Lamond, J., Proverbs, D. \& Dhonau, M., Availability and Uses of Property Level Flood Risk Data and Information, Department for Environment, Food and Rural Affairs, London, 2010.

[57] Chaochao, L., Cheng, X., Li, N., Du, X., Yu, Q. \& Kan, G., A framework for flood risk analysis and benefit assessment of flood control measures in urban areas. International Journal of Environmental Research and Public Health, 13(8), p. 787, 2016. https://doi.org/10.3390/ijerph13080787

[58] Lamond, J.E., Proverbs, D.G. \& Hammond, F.N., Accessibility of flood risk insurance in the UK: confusion, competition and complacency. Journal of Risk Research, 12, pp. 825-841, 2009.

https://doi.org/10.1080/13669870902768614

[59] Huang, P., Tan, H., Liu, A., Feng, S. \& Chen, M., 2010. Prediction of posttraumatic stress disorder among adults in flood district. BMC Public Health, 10(1), p. 207. https://doi.org/10.1186/1471-2458-10-207

[60] O’Sullivan, J.J., Bradford, R.A., Bonaiuto, M., De Dominicis, S., Rotko, P., Aaltonen, J., Waylen, K. \& Langan, S.J., Enhancing flood resilience through improved risk communications. Natural Hazards and Earth System Sciences, 12, pp. 2271-2282, 2012. https://doi.org/10.5194/nhess-12-2271-2012

[61] Buckle, P., Marsh, G. \& Smale, S., New approaches to assessing vulnerability and resilience. Australian Journal of Emergency Management, pp. 8-14, 2000.

[62] Tapsell, S.M. \& Tunstall, S.M., The Health Effects of Floods: The Easter 1998 Floods in England. Floods, ed. D.J. Parker. England: s.n., pp. 172-187, 2000.

[63] Tunstall, S., Tapsell, S., Green, C., Floyd, P. \& George, C., The health effects of flooding: social research results from England and Wales. Journal of Water and Health, 4(3), pp. 365-380, 2006.

https://doi.org/10.2166/wh.2006.031

[64] Pitt, M., Learning Lessons from the 2007 Floods, Cabinet Office, London, 2008. 